\title{
A fast algorithm for estimating transmission probabilities in QTL detection designs with dense maps Jean-Michel Elsen*1, Olivier Filangi ${ }^{2}$, Hélène Gilbert ${ }^{3}$, Pascale Le Roy ${ }^{2}$ and Carole Moreno ${ }^{1}$
}

\author{
Address: ${ }^{1}$ INRA, SAGA, BP27, 31326 Castanet Tolosan cedex, France, ${ }^{2}$ INRA, GARen, Agrocampus, 35000 Rennes, France and ${ }^{3}$ INRA, GABI, 78352 \\ Jouy en Josas cedex, France \\ Email: Jean-Michel Elsen* - Jean-Michel.Elsen@toulouse.inra.fr; Olivier Filangi - Olivier.Filangi@rennes.inra.fr; \\ Hélène Gilbert - Helene.Gilbert@jouy.inra.fr; Pascale Le Roy - Pascale.Leroy@rennes.inra.fr; Carole Moreno - Carole.Moreno@toulouse.inra.fr \\ * Corresponding author
}

Published: 17 November 2009

Genetics Selection Evolution 2009, 41:50 doi:10.1186/I297-9686-4I-50

This article is available from: http://www.gsejournal.org/content/4I///50

(C) 2009 Elsen et al; licensee BioMed Central Ltd.

This is an Open Access article distributed under the terms of the Creative Commons Attribution License (http://creativecommons.org/licenses/by/2.0), which permits unrestricted use, distribution, and reproduction in any medium, provided the original work is properly cited.
Received: 3 I July 2009

Accepted: 17 November 2009

\begin{abstract}
Background: In the case of an autosomal locus, four transmission events from the parents to progeny are possible, specified by the grand parental origin of the alleles inherited by this individual. Computing the probabilities of these transmission events is essential to perform QTL detection methods.
\end{abstract}

Results: A fast algorithm for the estimation of these probabilities conditional to parental phases has been developed. It is adapted to classical QTL detection designs applied to outbred populations, in particular to designs composed of half and/or full sib families. It assumes the absence of interference.

Conclusion: The theory is fully developed and an example is given.

\section{Background}

Experimental designs used for mapping QTL in livestock based on linkage analysis techniques generally comprise two or three generations. The younger generation consists of large offsprings (either half sib only or mixture of half and full sib) measured on quantitative traits to be dissected. This generation and in most cases their parents are genotyped for a set of molecular markers. Genotyping an older generation (the grand parents) helps the determination of parents' phases, an information essential to linkage analysis. QTL detection is a multiple step procedure. First the parental phases must be determined from grand parental and/or progeny genotype information, either looking for their most probable phase, or building all possible phases and computing their probabilities. Then transmission probabilities of chromosomal segments from the parents to the progeny must be estimated conditional to the phases. Finally a test statistic (e.g. F or likelihood ratio test), based on a given model (e.g. regression, mixture model, variance component model...) is performed at each putative QTL position on the chromosomal segments traced. In crosses between inbred lines, the transmission probabilities are simply obtained, as described by [1], from the information given by markers flanking the QTL. In outbred populations, the computation is not straightforward, due to the variability of marker informativity between families and within families between progenies. In $[2,3]$, the transmission probabilities were estimated conditionally to the sole flanking markers. [4-7] used a direct algorithm where all types of 
gametes corresponding to a linkage group are successively considered: if $L$ markers are heterozygous in the parent, $2^{L}$ gametes may be produced. This procedure is simple and computationnally fast for a small number of linked markers, but not feasible as soon as their number exceeds about 15. The difficulty can be circumvented in Bayesian approaches using MCMC techniques where these probabilities need not to be explicitly computed (e.g. [8]).

Nettelblad and colleagues [9] recently proposed a simple algorithm, which makes the transmission probabilities easily computable even for a large number of markers. In their approach the full length of the linkage group is still considered. A new algorithm, similar to the principle of [9] but exploring the minimum number of useful markers, was implemented in QTLMap software developed by INRA ([10]). Here, we describe and illustrate this algorithm.

\section{Hypotheses. Notations. Objective}

Progeny $p$ was born from sire $s$ and dam $d$. All were genotyped at $L$ loci $\left(M_{l}, l=1 \ldots L\right)$. The location of $M_{l}$ on the linkage group, i.e. its distance from one end of this group, is $x\left(M_{l}\right)$ centiMorgan, also denoted $x_{l}$. The hypothesis of absence of interference is made, allowing the Haldane distance function to be used.

The recombination rate between locus $l_{1}$ and $l_{2}$ will be noted $r_{l_{1}}, l_{2}$. Using the Haldane distance, $r_{l_{1}, l_{2}}=\frac{1}{2}\left(1-\exp \left\{-2\left(x_{l_{2}}-x_{l_{1}}\right)\right\}\right)$. When distances vary with sex, the superscript $m$ (for males) or $f$ (for females) will be used for $x_{l}$ and $r_{l_{1}}, l_{2}$.

Let the $l^{\text {th }}$ marker information be $P_{s l}=\left(P_{s l_{1}}, P_{s l_{2}}\right)$ for the sire, $P_{d l}=\left(P_{d l_{1}}, P_{d l_{2}}\right)$ for the dam, allele $P_{p l}=\left(P_{p l_{1}}, P_{p l_{2}}\right)$ for the progeny. In $P_{i l k^{\prime}} i=s, d$ or $p$, the subscript $k(k=1$, or 2 ) denotes the $k^{\text {th }}$ allele read in the records file.

The probabilities of transmission of a chromosomal segment from the parents to the progeny are estimated conditional to parental phases. A phase of parent $i$ ( $s$ or $d$ ) is characterised by a particular order of its marker phanotypes $P_{i}=\left\{P_{i l k}\right\}$, for loci $l=1$ to $L$, giving $G_{i}=\left\{G_{i l k}\right\}$ where $k=1$ means the grand sire allele and $k=2$ the grand dam allele. If grand parental origins cannot be built, one of the alleles of the first heterozygous marker in the parent to be phased is arbitrary assigned the subscript $k=1$.

Let $T\left(M_{l}\right)$ be the transmission event for marker $l$, and $T(M)$ the vector of transmission events on the linkage group: $T(M)=\left\{T\left(M_{1}\right), T\left(M_{2}\right) \cup T\left(M_{L}\right)\right\} . T\left(M_{s}\right)$ and $T\left(M_{d}\right)$ are respectively the transmission events from the sire and from the dam to the progeny. $T\left(M_{i l}\right)=k$ if the progeny received $G_{i l k}, i=s$ or $d$. If the grand parental origins are known, progeny $p$ may have received alleles from both its grand sires $\left(T\left(M_{s l}\right)=1\right.$ and $T\left(M_{d l}\right)=1$, thus $\left.T\left(M_{l}\right)=11\right)$, from its paternal grand sire and maternal grand dam $\left(T\left(M_{l}\right)=12\right)$, from its paternal grand dam and maternal grand sire $\left(T\left(M_{l}\right)=21\right)$, or from both its grand dams $\left(T\left(M_{l}\right)=22\right)$. The probabilities of the transmission events, given the marker phenotypes and parental phases are listed in Table 1 for a biallelic marker.

The 16 situations described in Table 1 belong to five types:

- Type 'ksd' : Transmission fully known for both parents (cases 1 to 4 ),

- Type 'ks0': Transmission known for the sire only (cases 5 to 8 ),

- Type 'k0d': Transmission known for the dam only (cases 9 to 12),

- Type 'k00': Unknown Transmission (cases 13 and 14),

- Type 'amb': Ambiguous Transmission (case 15 and 16).

The $a m b$ type corresponds to fully heterozygous trios. It is essential to note that this is the only type of marker phenotypes for which the sire and dam transmissions are not independent (e.g. in situation 15, if sire transmits 1, dam transmits 2 and the reverse).

When the information about one or both parents is missing the conditionnal probability of $T\left(M_{l}\right)$ most often corresponds to the $k 00$ type $[1 / 4,1 / 4,1 / 4,1 / 4]$. However, when only one parent possesses a marker phanotype and is phased heterozygous $(a, b)$, the probabilities are $[1 / 2,0$, $1 / 2,0]$ if $P_{p l}=(a, a)$ and $[0,1 / 2,0,1 / 2]$ if $P_{p l}=(b, b)$.

Two properties of the transmission probabilities must be underlined:

Property 1: Marginally to the marker phenotype, the sire and dam transmission events are independent: $P\left[T\left(M_{l}\right)\right]=$ $P\left[T\left(M_{s l}\right)\right] . P\left[T\left(M_{d l}\right)\right]$.

Property 2: Due to the no interference hypothesis, the transmission events follow a Markovian process described by:

$P[T(M)]=P\left[T\left(M_{1}\right)\right] \cdot P\left[T\left(M_{2}\right) \mid T\left(M_{1}\right)\right] \cdot P\left[T\left(M_{3}\right) \mid T\left(M_{2}\right)\right] \cdots P\left[T\left(M_{L}\right) \mid T\left(M_{L-1}\right]\right.$ 
Table I: $P\left[T\left(M_{l}\right) \mid G_{s l}, G_{d l}, P_{p l}\right]$ : Probabilities of the transmission events, given the marker phenotypes and parental phases, in the case of a biallelic marker ( $a, b$ alleles)

\begin{tabular}{|c|c|c|c|c|c|c|c|c|c|}
\hline \multirow[b]{2}{*}{ Case } & \multirow[b]{2}{*}{$G_{s l_{1}}$} & \multirow[b]{2}{*}{$G_{s l_{2}}$} & \multirow[b]{2}{*}{$G_{d l_{1}}$} & \multirow[b]{2}{*}{$G_{d l_{2}}$} & \multirow[b]{2}{*}{$P_{p l}$} & \multicolumn{4}{|c|}{$P\left(T\left(M_{1}\right) \mid G_{s l}, G_{d l}, P_{p l}\right)$ for $T\left(M_{l}\right)=$} \\
\hline & & & & & & 11 & 12 & 21 & 22 \\
\hline 1 & $\mathrm{a}$ & $b$ & a & $b$ & $(a, a)$ & I & & & \\
\hline 2 & a & $\mathrm{b}$ & $\mathrm{a}$ & $\mathrm{b}$ & $(b, b)$ & & & & I \\
\hline 3 & a & $\mathrm{b}$ & $b$ & $\mathrm{a}$ & $(a, a)$ & & 1 & & \\
\hline 4 & a & $\mathrm{b}$ & $\mathrm{b}$ & a & $(b, b)$ & & & 1 & \\
\hline 5 & $\mathrm{a}$ & $b$ & $\mathrm{a}$ & $\mathrm{a}$ & $(a, a)$ & $\mathrm{I} / 2$ & $\mathrm{I} / 2$ & & \\
\hline 6 & a & $\mathrm{b}$ & $\mathrm{a}$ & a & $(a, b)$ or $(b, a)$ & & & $\mathrm{I} / 2$ & $1 / 2$ \\
\hline 7 & b & $\mathrm{a}$ & a & a & $(a, a)$ & & & $\mathrm{I} / 2$ & $1 / 2$ \\
\hline 8 & $\mathrm{~b}$ & $\mathrm{a}$ & $\mathrm{a}$ & $\mathrm{a}$ & $(a, b)$ or $(b, a)$ & $1 / 2$ & $1 / 2$ & & \\
\hline 9 & $\mathrm{a}$ & $\mathrm{a}$ & $\mathrm{a}$ & $b$ & $(a, a)$ & $\mathrm{I} / 2$ & & $\mathrm{I} / 2$ & \\
\hline 10 & a & $\mathrm{a}$ & $\mathrm{a}$ & b & $(a, b)$ or $(b, a)$ & & $\mathrm{I} / 2$ & & $1 / 2$ \\
\hline 11 & a & $\mathrm{a}$ & $b$ & a & $(a, a)$ & & $\mathrm{I} / 2$ & & $1 / 2$ \\
\hline 12 & a & $\mathrm{a}$ & $b$ & a & $(a, b)$ or $(b, a)$ & $1 / 2$ & & $1 / 2$ & \\
\hline 13 & $\mathrm{a}$ & $\mathrm{a}$ & $\mathrm{a}$ & $\mathrm{a}$ & $(a, a)$ & $1 / 4$ & $1 / 4$ & $1 / 4$ & $1 / 4$ \\
\hline 14 & a & $\mathrm{a}$ & b & $\mathrm{b}$ & $(a, b)$ & $\mathrm{I} / 4$ & $1 / 4$ & $\mathrm{I} / 4$ & $1 / 4$ \\
\hline 15 & $\mathrm{a}$ & $b$ & $\mathrm{a}$ & $b$ & $(a, b)$ or $(b, a)$ & & $1 / 2$ & $1 / 2$ & \\
\hline 16 & a & $b$ & $b$ & a & $(a, b)$ or $(b, a)$ & $1 / 2$ & & & $1 / 2$ \\
\hline
\end{tabular}

$G_{i k k}$ is the allele marker $/$ the parent $i$ is carrying on its $k^{\text {th }}$ chromosome $\left((k=(I, 2)) ; P_{p l}\right.$ is the marker $/$ phenotype of the progeny; $T\left(M_{l}\right)=$ is the transmission event at marker $I$

Note that property 2 is also valid when considering subsets of $M, M_{b}$ and $M_{a^{\prime}}$ allowing an independent estimation of probabilities before and after a given marker $M_{c}$. If $M=$ $\left\{M_{b}, M_{c}, M_{a}\right\}$

$$
P[T(M)]=P\left[T\left(M_{b}\right) \mid T\left(M_{c}\right)\right] \cdot P\left[T\left(M_{c}\right)\right] \cdot P\left[T\left(M_{a}\right) \mid T\left(M_{c}\right)\right]
$$

At any position $x$ for a QTL, four grand parental origins are possible for the chromosomal segment $Q_{x}$ inherited by the progeny. Let $q=\left(q_{s^{\prime}} q_{d}\right),(q=(11),(12),(21)$ or (22)), the origin of $Q_{x}$.

The objective is to estimate $P_{x}(q)=P\left[T\left(Q_{x}\right)=q \mid G_{s^{\prime}} G_{d^{\prime}}\right.$ $\left.P_{p}\right]$, the probability of $q$ given the marker information.

To minimize the computation, two procedures are presented: the first one is an iterative exploration of the linkage group, the second a reduction of this group within bounds specific of the tested position $x$.

\section{Iterative exploration of the linkage group}

The observed marker phenotypes and parents' phases can be consistent with different transmission events $T(M)$. All these events must be considered in turn when evaluating the QTL transmission $T\left(Q_{x}\right)$. For a given marker transmission event, markers must be successively considered, the no interference hypothesis allowing an iterative estimation of the probability.
Proposition 1 : Let $\Omega$ be the domain, for the progeny $p$, of transmissions $T(M)$ consistent with the observations $G_{s^{\prime}}$ $G_{d}$ and $P_{p}$. The transmission probability $P_{x}(q)$ is given by:

$$
P\left[T\left(Q_{x}\right)=q \mid G_{s^{\prime}} G_{d}, P_{p}\right]=\frac{\sum_{T(M) \in \Omega} P\left[T\left(Q_{x}\right)=q, T(M)\right]}{\sum_{T(M) \in \Omega} P[T(M)]}
$$

This is obtained after very simple algebra (see appendix).

The domain $\Omega$ is obtained listing possible transmissions. If $\Omega_{l}$ is the consistent domain for marker $l$, the $\Omega$ domain is formed of nested domains $\Omega_{1} \oplus \Omega_{2} \oplus \cup \oplus \Omega_{L} \cdot \Omega_{l}$ is directly obtained from Table 1: it is formed of transmission events the probability of which are not nul. For instance, if $G_{s}=a a, G_{d}=a b$ and $P_{p}=a a$, then $\Omega_{l}=\{11,12\}$.

In the following we shall note $S_{\Omega}=\sum_{T(M) \in \Omega} P[T(M)]$ and $T_{\Omega}=\sum_{T(M) \in \Omega} P\left[T\left(Q_{x}\right)=q, T(M)\right]$.

Proposition 2 : The summation $S_{\Omega}=\sum_{T(M) \in \Omega} P[T(M)]$ in (1) can be obtained recursively with the following algorithm:

\[ S_{\Omega}=\sum_{T\left(M_{L}\right) \in \Omega_{L}} F\left[T\left(M_{L}\right)\right] \]
With $F\left[T\left(M_{l}\right)\right]=\sum_{T\left(M_{l-1}\right) \in \Omega_{l-1}} P\left[T\left(M_{l}\right) \mid T\left(M_{l}-1\right)\right] . F\left[T\left(M_{l}-1\right)\right]$
And $F\left[T\left(M_{l}\right)\right]=P\left[T\left(M_{l}\right)\right]$ 
This is obtained under the hypothesis of absence of interference (see appendix).

Note 1: the numerator of (1) is obtained similarly, considering the extended domain $\Omega^{*}=\Omega_{1} \oplus \Omega_{2} \ldots \oplus \Omega_{x} \ldots \oplus \Omega_{L^{\prime}}$ with $\Omega_{x}=q$.

Note 2: The $P\left[T\left(M_{l}\right) \mid T\left(M_{l-1}\right)\right]$ are simply obtained as given in Table 2, for $k=l-1$.

They may be summarized by a single formulae. Let $\theta\langle r, i, j\rangle$ $=1-r-(1-2 r) \cdot(i-j)^{2}$,

$$
P\left[T\left(M_{l}\right) \mid T\left(M_{k}\right)\right]=\theta\left\langle r_{l, k}^{m}, T\left(M_{s k}\right), T\left(M_{s l}\right)\right\rangle \cdot \theta\left\langle r_{l, k^{\prime}}^{f}, T\left(M_{d k}\right), T\left(M_{d l}\right)\right\rangle
$$

Note 3: System (2) may be generalized to any subdivision of the linkage group $M, M=\left\{M_{1}, M_{2}, \ldots M_{G}\right\}$, defining $T\left(M_{g}\right), g=1 \ldots G$, as the vector of $T\left(M_{l}\right), l \in M_{g}$.

\section{Reduction of the linkage group}

The set of markers $M=\left\{M_{l}, l=1 \ldots L\right\}$ may be sequenced as $M=\left\{M_{a^{\prime}} M_{\alpha^{\prime}} M_{c^{\prime}} M_{\beta^{\prime}} M_{b}\right\}$ where $M_{c}$ is a subset of interest, $M_{\beta}$ and $M_{\alpha}$ its flanking markers, and $M_{b}$ and $M_{a}$ all the remaining markers before and after the area $\left(M_{\alpha^{\prime}} M_{c^{\prime}} M_{\beta}\right)$. We now propose three simplifications of the summation $S_{\Omega}=\sum_{T(M) \in \Omega} P[T(M)]$.

Proposition 3 : In the summation $S_{\Omega^{\prime}}$ the type $k 00$ markers can be ignored, i.e. they may be bypassed in the iterative system (2).

Here $M_{c}$ is a single $k 00$ type marker. Proposition 3 means (see appendix for a demonstration) that, in (2), the sequence:

$$
F\left[T\left(M_{\beta}\right)\right]=\sum_{T\left(M_{c} \in \in \Omega_{c}\right.} P\left[T\left(M_{\beta}\right) \mid T\left(M_{c}\right)\right]\left\{\sum_{T\left(M_{\alpha}\right) \in \Omega_{\alpha}} P\left[T\left(M_{c}\right) \mid T\left(M_{\alpha}\right)\right] \cdot F\left[T\left(M_{\alpha}\right)\right]\right\}
$$

which corresponds to two iterations, may be replaced by:

$$
F\left[T\left(M_{\beta}\right)\right]=\sum_{T\left(M_{\alpha}\right) \in \Omega(\alpha)} P\left[T\left(M_{\beta}\right) \mid T\left(M_{\alpha}\right)\right] \cdot F\left[T\left(M_{\alpha}\right)\right]
$$

Proposition 4: In the summation $S_{\Omega^{\prime}}$ the elements corresponding to the unknown parental transmission for types $k 0 d$ or $k s 0$ markers can be ignored, i.e. they may be bypassed in the iterative system (2).

Here $M_{c}$ is a single $k s 0$ or $k 0 d$ type marker. Proposition 4 means (see appendix for a demonstration) that, in (2), the sequence

$$
F\left[T\left(M_{\beta}\right)\right]=\sum_{T\left(M_{c} \in \Omega_{c}\right.} P\left[T\left(M_{\beta}\right) \mid T\left(M_{c}\right)\right]\left\{\sum_{T\left(M_{\alpha}\right) \in \Omega_{\alpha}} P\left[T\left(M_{c}\right) \mid T\left(M_{\alpha}\right)\right] \cdot F\left[T\left(M_{\alpha}\right)\right]\right\}
$$

which corresponds to two iterations, may be replaced by (successively $k 0 d$ and $k s 0$ markers):

$$
\begin{aligned}
& F\left[T\left(M_{\beta}\right)\right]=P\left[T\left(M_{d \beta}\right) \mid T\left(M_{d c}\right)\right] \sum_{T\left(M_{\alpha}\right) \in \Omega(\alpha)} P\left[T\left(M_{d c}\right) \mid T\left(M_{d \alpha}\right)\right] \cdot P\left[T\left(M_{s \beta}\right) \mid T\left(M_{s \alpha}\right)\right] \cdot F\left[T\left(M_{\alpha}\right)\right] \\
& F\left[T\left(M_{\beta}\right)\right]=P\left[T\left(M_{s \beta}\right) \mid T\left(M_{s c}\right)\right] \sum_{T\left(M_{\alpha}\right) \in \Omega(\alpha)} P\left[T\left(M_{s c}\right) \mid T\left(M_{s \alpha}\right)\right] \cdot P\left[T\left(M_{d \beta}\right) \mid T\left(M_{d \alpha}\right)\right] \cdot F\left[T\left(M_{\alpha}\right)\right]
\end{aligned}
$$

Corollary 1: In the summation $S_{\Omega^{\prime}}$ a sequence $M_{c}$ of mark-

\begin{tabular}{|c|c|c|c|c|}
\hline$T\left(M_{k}\right)$ & II & 12 & 21 & 22 \\
\hline \multicolumn{5}{|l|}{$T\left(M_{l}\right)$} \\
\hline 11 & $\left(1-r_{l, k}^{m}\right) \cdot\left(1-r_{l, k}^{f}\right)$ & $\left(1-r_{l, k}^{m}\right) r_{l, k}^{f}$ & $r_{l, k}^{m}\left(1-r_{l, k}^{f}\right)$ & $r_{l, k}^{m} r_{l, k}^{f}$ \\
\hline 12 & $\left(1-r_{l, k}^{m}\right) r_{l, k}^{f}$ & $\left(1-r_{l, k}^{m}\right)\left(1-r_{l, k}^{f}\right)$ & $r_{l, k}^{m} r_{l, k}^{f}$ & $r_{l, k}^{m}\left(1-r_{l, k}^{f}\right)$ \\
\hline 21 & $r_{l, k}^{m}\left(1-r_{l, k}^{f}\right)$ & $r_{l, k}^{m} r_{l, k}^{f}$ & $\left(1-r_{l, k}^{m}\right)\left(1-r_{l, k}^{f}\right)$ & $\left(1-r_{l, k}^{m}\right) r_{l, k}^{f}$ \\
\hline 22 & $r_{l, k}^{m} r_{l, k}^{f}$ & $r_{l, k}^{m}\left(1-r_{l, k}^{f}\right)$ & $\left(1-r_{l, k}^{m}\right) r_{l, k}^{f}$ & $\left(1-r_{l, k}^{m}\right)\left(1-r_{l, k}^{f}\right)$ \\
\hline
\end{tabular}
ers all belonging to " $k$ " types (i.e. non $a m b$ ) appears as a single element where only the certain transmissions are involved.

From propositions 3 and 4,

Table 2: Transmission probability at locus I given the transmission at locus $k: P\left[T\left(M_{l}\right) \mid T\left(M_{k}\right)\right]$

$r_{l, k}^{i}$ is the recombination rate for sex $i$, between loci $/$ and $k$. 


$$
\begin{aligned}
F\left[T\left(M_{\beta}\right)\right]= & P\left[T\left(M_{d \beta}\right) \mid T\left(M_{d c_{1}}\right)\right] \cdot\left\{\prod_{j_{d}=1 \cdots J_{D}} P\left[T\left(M_{d c_{j d+1}}\right) \mid T\left(M_{d c_{j d}}\right)\right]\right\} \\
& P\left[T\left(M_{s \beta}\right) \mid T\left(M_{s c_{1}}\right)\right] \cdot\left\{\prod_{j_{s}=1 \cdots J_{s}} P\left[T\left(M_{s c_{j_{s}+1}}\right) \mid T\left(M_{s c_{j_{s}}}\right)\right]\right\} \\
& \sum_{T\left(M_{\alpha}\right) \in \Omega_{\alpha}} P\left[T\left(M_{d c_{d d}}\right) \mid T\left(M_{d \alpha}\right)\right] \cdot P\left[T\left(M_{s c_{s}}\right) \mid T\left(M_{s \alpha}\right)\right] \cdot F\left[T\left(M_{\alpha}\right)\right]
\end{aligned}
$$

where the markers subscripted $j_{s}\left(=1 \cup J_{s}\right)$ are successive markers belonging to $k s d$ or $k s 0$ types, and the markers subscripted $j_{d}\left(=1 \cup J_{d}\right)$ to $k s d$ or $k 0 d$ types in the sequence $M_{c}$.

Definition : A series of markers $N=\left\{M_{\alpha^{\prime}} M_{c^{\prime}} M_{\beta}\right\}$ starting with a $k s 0$ (resp. $k 0 d)$ type marker $\left\{M_{\alpha}\right\}$, ending with a $k 0 d$ (resp. ks0) type marker $\left\{M_{\beta}\right\}$, and only with $k 00$ type markers between those bounds (in $M_{c}$ ) will be called a sdnode (resp. ds-node).

Proposition 5: If the sequence $N=\left\{M_{\alpha^{\prime}} M_{c^{\prime}} M_{\beta}\right\}$ of $M$ is a sd-node, the summation $S_{\Omega}$ may be separated in three terms corresponding to $\left[M_{b} / M_{\beta s^{\prime}} M_{\alpha d}\right],\left[M_{\beta s^{\prime}} M_{\alpha d}\right]$, and $\left[M_{a} / M_{\beta s^{\prime}} M_{\alpha d}\right]$ Proposition 5 means (see appendix for a demonstration) that, in (2), $S_{\Omega}$ is obtained by

$$
\begin{aligned}
S_{\Omega}= & \left\{\sum_{T\left(M_{b}\right) \in \Omega_{b}} \sum_{T\left(M_{d \beta}\right) \in \Omega_{\beta b}} P\left[T\left(M_{b}\right), T\left(M_{d \beta}\right) \mid T\left(M_{s \beta}\right), T\left(M_{d \alpha}\right)\right]\right\} . \\
& P\left[T\left(M_{s \beta}\right), T\left(M_{d \alpha}\right)\right] . \\
& \left\{\sum_{T\left(M_{\alpha}\right) \in \Omega_{\alpha}} \sum_{T\left(M_{s \alpha}\right) \in \Omega_{s \alpha}} P\left[T\left(M_{a}\right), T\left(M_{s \alpha}\right) \mid T\left(M_{s \beta}\right), T\left(M_{d \alpha}\right)\right]\right\}
\end{aligned}
$$

Note 4: The $\left\{M_{\beta^{\prime}}, M_{c^{\prime}} M_{\alpha}\right\}$ sequence may be reduced to a single marker $M_{\gamma}$ if it belongs to the $k s d$ type. In this case,

$$
S_{\Omega}=\left\{\sum_{T\left(M_{b}\right) \in \Omega_{b}} P\left[T\left(M_{b}\right) \mid T\left(M_{\gamma}\right)\right]\right\} . P\left[T\left(M_{\gamma}\right)\right] \cdot\left\{\sum_{T\left(M_{a}\right) \in \Omega_{a}} P\left[T\left(M_{a}\right) \mid T\left(M_{\gamma}\right)\right]\right\}
$$

In general we shall note $T(N)$ the transmission event for a node, $\left\{T\left(M_{s \beta}\right), T\left(M_{d \alpha}\right)\right\},\left\{T\left(M_{d \beta}\right), T\left(M_{s \alpha}\right)\right\}$ or $T\left(M_{\gamma}\right)$.

Corollary 2: If the tested QTL position $x$ is located in segment $M_{c}$ between two nodes $N_{1}$ and $N_{2}$, only the markers belonging to the interval $\left[N_{1}, N_{2}\right]$ have to be considered when computing the transmission probability $P\left[T\left(Q_{x}\right)=q\right.$ | $\left.G_{s^{\prime}} G_{d^{\prime}} P_{p}\right]$, see appendix, giving:

$P\left[T\left(Q_{x}\right)=q \mid G_{s}, G_{d}, P_{p}\right]=\frac{\Sigma_{T\left(M_{\mathcal{C}}\right) \in \Omega_{C}} P\left[T\left(Q_{x}\right)=q, T\left(N_{1}\right), T\left(M_{\mathcal{C}}\right), T\left(N_{2}\right)\right]}{\Sigma_{T\left(M_{\mathcal{C}}\right) \in \Omega_{C}} P\left[T\left(N_{1}\right), T\left(M_{\mathcal{C}}\right), T\left(N_{2}\right)\right]}$

\section{Algorithm}

Based on the propositions and corollaries developed above, an algorithm for the computation of transmission probabilities of the chromosomic segment $x$ can be given.
1. From the position $x$, the markers are explored towards the left until a node (a $k s d$ type marker or a pair of markers one of $k s 0$ and the other of $k 0 d$ type, separated only by $k 00$ type markers) or the extremity of the linkage group is found. Let $T\left(N_{l}\right)$ be the transmission events for the left node $N_{l} . P\left[T\left(N_{l}\right)\right]=1 / 4$.

2. From the position $x$, the markers are explored towards the right until a node or the extremity of the linkage group is found. Let $T\left(N_{r}\right)$ be the transmission events for the right node $N_{r} . P\left[T\left(N_{r}\right)\right]=1 / 4$. The only necessary informative segment for $x$ in the full linkage group is $\left\{N_{l}, N_{r}\right\}$.

3. Let $M_{a_{1}}, M_{a_{2}}, \cdots, M_{a_{n}}$ the amb type markers in $\left\{N_{l}\right.$, $N_{r}$ \}. Together with $N_{l}$ and $N_{r^{\prime}}$ the $M_{a_{k}}$ delimit $n+1$ intervals $I_{k}$, which may be empty or include $k 00, k s 0$ or k0d type markers. The reduced summation $S_{\Omega}^{r}$, see (the part of $S_{\Omega}$ which differs from $T_{\Omega}$ and has to be used in $P_{x}(q)=\frac{S_{\Omega}}{T_{\Omega}}=\frac{S_{\Omega}^{r}}{T_{\Omega}^{r}}$ see appendix) is computed iteratively:

$$
\begin{aligned}
S_{\Omega}^{r}= & F\left[T\left(N_{r}\right)\right] \\
\text { With } \quad F\left[T\left(N_{r}\right)\right]= & \sum_{T\left(M_{a_{n}}\right) \in \Omega_{a_{n}}} P\left[T\left(N_{r}\right) \mid T\left(M_{a_{n}}\right)\right] \cdot F\left[T\left(M_{a_{n}}\right)\right] \\
\text { Then } \quad F\left[T\left(M_{a_{l}}\right)\right]= & \sum_{T\left(M_{a_{l-1}}\right) \in \Omega_{a_{l-1}}} P\left[T\left(M_{a_{l}}\right) \mid T\left(M_{a_{l-1}}\right)\right] \cdot F\left[T\left(M_{a_{l-1}}\right)\right] \\
& \\
\text { And } \quad F\left[T\left(M_{a_{1}}\right)\right]= & P\left[T\left(M_{a_{1}}\right) \mid T\left(N_{l}\right)\right] \cdot P\left[T\left(N_{l}\right)\right]
\end{aligned}
$$

It must be underlined that there is no node between two adjacent $a m b$ type markers of the informative segment $\left\{N_{l}, N_{r}\right\}$, since this segment ends at the first node found on both sides. As a consequence, neither a $k s d$ marker type nor a mixture of $k s 0$ and $k 0 d$ types markers could be found between the ambiguous markers $M\left(a_{k}\right)$ and $M\left(a_{k+1}\right)$ : the $I_{k}$ interval may be classified as $K 00$ (only $k 00$ types markers), KsO (one or more $k s 0$ type markers, no kod type marker and any number of $k 00$ type markers) or $K 0 d$ (the reverse).

4. Let $M_{a_{k}}$ and $M_{a_{k+1}}$ be two successive $a m b$ markers, in the iterative process (4), the probabilities $P$ $\left[T\left(M_{a_{k+1}}\right) / T\left(M_{a_{k}}\right)\right]$ are given by

K00 interval $\theta\left\langle r_{a_{k}, a_{k+1}}^{m}, T\left(M_{s a_{k}}\right), T\left(M_{s a_{k+1}}\right)\right\rangle \cdot \theta\left\langle r_{a_{k}, a_{k+1}}^{f}, T\left(M_{d a_{k}}\right), T\left(M_{d a_{k+1}}\right)\right\rangle$

Ks0 interval $\left\{\prod_{i \in I_{k}} \theta\left\langle r_{i-1, i}^{m}, T\left(M_{s i-1}\right), T\left(M_{s i}\right)\right\rangle\right\} \cdot \theta\left\langle r_{a_{k}, a_{k+1}}^{f}, T\left(M_{d a_{k}}\right), T\left(M_{d a_{k+1}}\right)\right\rangle$

Kod interval $\theta\left\langle r_{a_{k}, a_{k+1}}^{m}, T\left(M_{s a_{k}}\right), T\left(M_{s a_{k+1}}\right)\right\rangle \cdot\left\{\prod_{i \in I_{k}} \theta\left\langle r_{i-1, i}^{f}, T\left(M_{d i-1}\right), T\left(M_{d i}\right)\right\rangle\right\}$ 
where $\theta\langle r, i, j\rangle=1-r-(1-2 r) \cdot(i-j)^{2}$.

5. The reduced summation $T_{\Omega}^{r}$ is computed iteratively adding the $T\left(Q_{x}\right)$ transmission in the list of transmission $\left\{T\left[N_{l}\right], T\left[M_{a_{1}}\right], \cup, T\left[M_{a_{n}}\right], T\left[N_{r}\right]\right\}$.

6. The transmission probability $P\left[T\left(Q_{x}\right)=q \mid G_{s^{\prime}} G_{d^{\prime}}\right.$ $\left.P_{p}\right]=T_{\Omega}^{r} / S_{\Omega}^{r}$.

Note 5: The algorithm can be organised scanning the interval $\left\{N_{l}, N_{r}\right\}$ from the left to the right rather than from the right to the left as described above.

\section{Example}

A linkage group of eight markers is available (Figure 1). Markers $M_{2}$ and $M_{6}$ are ambiguous, with types 15 and 16 . Markers 1 and 8 are fully informative (types 1 and 2), the other markers are semi informative. The tested position for the QTL $x$ is located between markers 4 and 5. The nodes are, on the left, marker 1 ( $k s d$ type) and on the right, the group $M_{7}-M_{8}$. Thus the informative segment here is the full group. Steps of the proposed algorithm are detailed Table 3.

\section{Discussion - Conclusion}

The algorithm presented in this paper to estimate the transmission probability of QTL from parents to progeny needs only very limited computational resources, both in terms of time and space. Complementary to the algorithm presented by Nettleblad and colleagues (2009), it limits the exploration of the linkage group to the markers really informative for a given position to be traced, and thus performs faster. As [9], it deals with sex differences between recombination rates.

The QTL transmission probability is estimated conditionnaly to the observed transmission at the surrounding markers loci. The algorithm does not make use of possible

Table 3: Calculation of the marker transmission probability corresponding to the example in Figure I

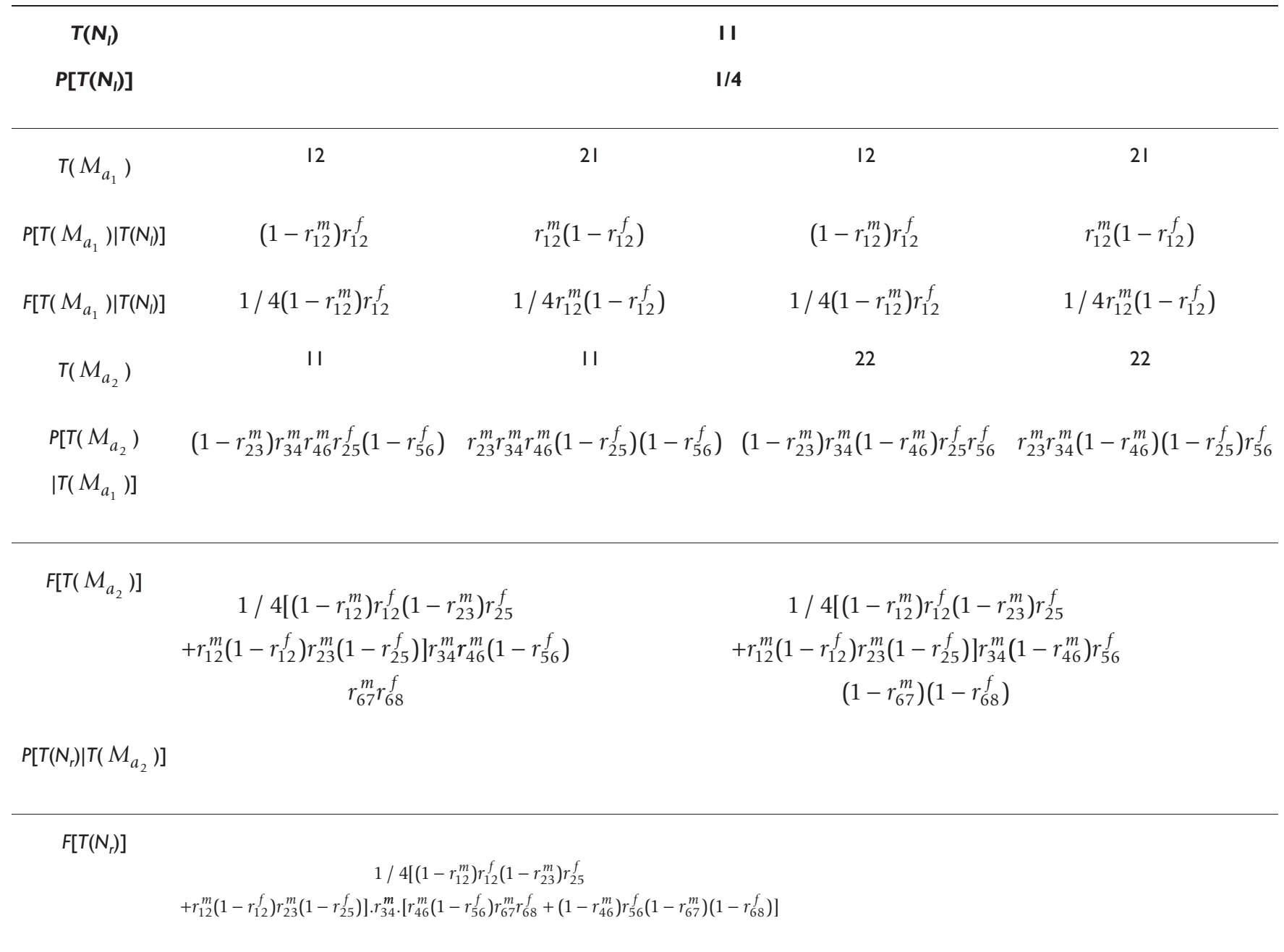




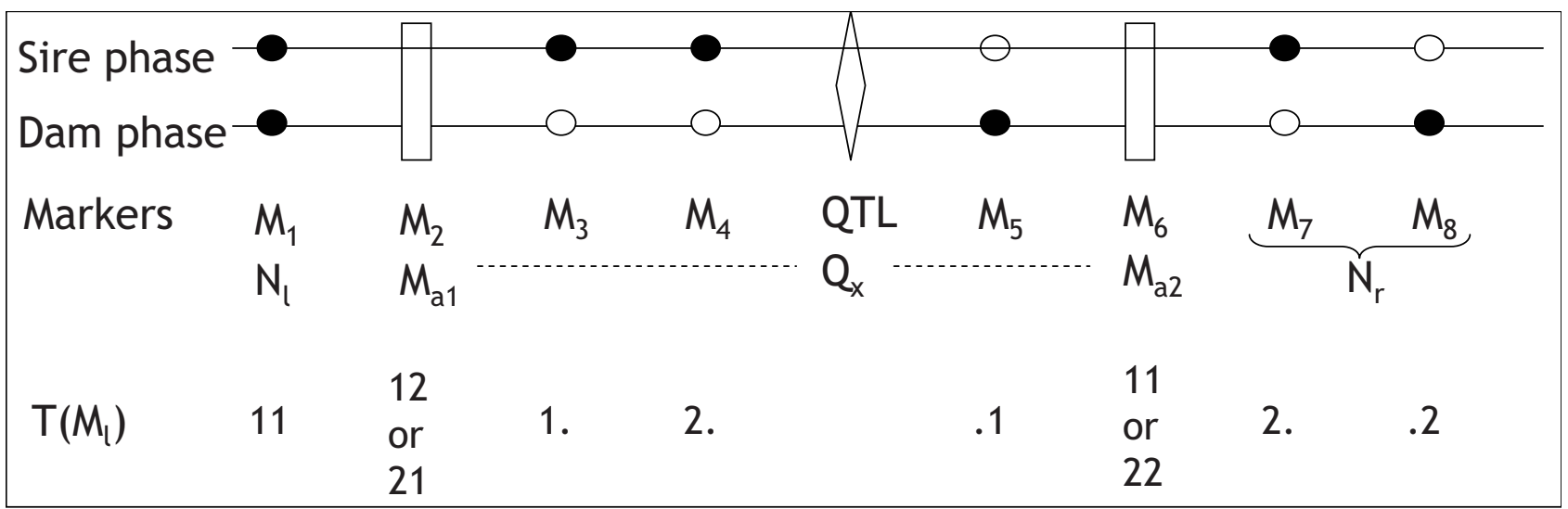

• (resp. 0 ) known (resp. unknown) parental origin
\[ \begin{array}{l}\text { Ambiguous marker } \\ \text { QTL position }\end{array} \]

Figure I

Example of a linkage group with 8 markers including $\mathbf{2}$ ambigous. The figure represents a chromosome with eight markers. Two $\left(M_{2}\right.$ and $\left.M_{6}\right)$ are ambiguous (For $M_{2}$, the progeny received either the Ist allele of its sire and $2^{\text {nd }}$ allele of its dam, or the $2^{\text {nd }}$ of its sire and Ist of its dam. The nodes are, on the left, the first marker, and on the right, markers $M_{7}$ and $M_{8}$. The dark (respectively white) circles represent markers with a known (respectively unknown) grand parental origin.

information about the marker allele frequencies to fill potential information gaps.

The major difficulty addressed in this algorithm is the non independence of transmission events from the sire and the dam to the progeny in triple heterozygous trios. In the absence of such trios, the transmission from the parents are fully independent and may be treated separately simply by considering the flanking informative markers. This is the case for QTL located on the sex chromosome X or W.

The algorithm has been developed in the framework of QTL detection designs involving two or three generations in outbred populations. It has been implemented in QTLMap, a software for the analysis of such designs. QTLMap is available upon request to the authors.

In more complex pedigrees, the transmission probability should not be conditioned only on parents phases and progeny marker phanotypes. Information from the grand progeny (and the spouses lineages) may improve the estimation, since the progeny phase can be inferred, at least partially, from these data. A recursive process inspirated from [3] should possibly be implemented.

The transmission probabilities are estimated conditionally to parental phases. In linear approaches (e.g. the Haley Knott regression), if more than one phase is proba- ble, the marginal transmission probability could be estimated considering all of them in a weighted sum of conditional probabilities. Alternatively, the only most probable phase could be considered [11].

The absence of interference hypothesis is central in the present algebra. If this is not true, then most of the propositions are not valid and the algorithm not applicable.

Finally, compared to the most common codominant markers, dominant markers will be characterized by a lower informativity, with an increase of the between nodes segment length and a concomitant decrease of the transmission probability.

\section{Competing interests}

The authors declare that they have no competing interests.

\section{Authors' contributions}

JME drafted the manuscript. All authors participated in the development of the method and read and approved the final manuscript. 


\section{Appendix: Demonstration of the propositions} and corollary

Proposition 1: $P\left[T\left(Q_{x}\right)=q \mid G_{s^{\prime}} \quad G_{d^{\prime}} \quad P_{p}\right]=$ $\frac{\Sigma_{T(M) \in \Omega} P\left[T\left(Q_{x}\right)=q, T(M)\right]}{\Sigma_{T(M) \in \Omega^{P}}[T(M)]}$

$$
\begin{aligned}
P\left[T\left(Q_{x}\right)=q \mid G_{s}, G_{d}, P_{p}\right] & =\frac{P\left[T\left(Q_{x}\right)=q, P_{p} \mid G_{s}, G_{d}\right]}{P\left[P_{p} \mid G_{s}, G_{d}\right]} \\
P\left[P_{p} \mid G_{s^{\prime}}, G_{d}\right] & =\sum_{T(M)} P\left[T(M), P_{p} \mid G_{s^{\prime}}, G_{d}\right] \\
\text { and } P\left[T\left(Q_{x}\right)=q, P_{p} \mid G_{s^{\prime}}, G_{d}\right] & =\sum_{T(M)} P\left[T(M), T\left(Q_{x}\right)=q, P_{p} \mid G_{s^{\prime}}, G_{d}\right] \\
P\left[T(M), P_{p} \mid G_{s^{\prime}}, G_{d}\right] & =P\left[P_{p} \mid T(M), G_{s}, G_{d}\right] . P\left[T(M) \mid G_{s^{\prime}}, G_{d}\right] \\
P\left[P_{p} \mid T(M), G_{s}, G_{d}\right] & =1 \text { if } T(M) \in \Omega \\
& =0 \text { if not } \\
P\left[T(M) \mid G_{s}, G_{d}\right] & =P[T(M)]
\end{aligned}
$$

And, similarly, $P\left[T\left(Q_{x}\right)=q, P_{p} \mid G_{s^{\prime}} G_{d}\right]=P\left[T\left(Q_{x}\right)=q\right.$, $T(M)]$ if $T(M) \in \Omega_{,}=0$ if not

\section{Proposition 2}

Due to the no interference hypothesis, the transmission events follow a Markovian process described by:

$P[T(M)]=P\left[T\left(M_{1}\right)\right] \cdot P\left[T\left(M_{2}\right) \mid T\left(M_{1}\right)\right] \cdot P\left[T\left(M_{3}\right) \mid T\left(M_{2}\right)\right] \cdots P\left[T\left(M_{L}\right) \mid T\left(M_{L-1}\right)\right]$ Thus

$$
\begin{aligned}
S_{\Omega} & =\sum_{T(M) \in \Omega} P[T(M)] \\
& =\sum_{T\left(M_{1}\right) \in \Omega_{1}} \sum_{T\left(M_{2}\right) \in \Omega_{2}} \cdots \sum_{T\left(M_{L}\right) \in \Omega_{L}} P\left[T\left(M_{1}\right)\right] . \prod_{l=2 \cdots L} P\left[T\left(M_{l}\right) \mid T\left(M_{l-1}\right)\right]
\end{aligned}
$$

The summations may be inverted:

$$
\begin{aligned}
S_{\Omega} & =\sum_{T\left(M_{L}\right) \in \Omega_{L}} \sum_{T\left(M_{L-1)} \in \Omega_{L-1}\right.} P\left[T ( M _ { L } ) | T ( M _ { L - 1 } ) | \left\{\sum_{T\left(M_{L-2}\right) \in \Omega_{L-2}} P\left[T\left(M_{L-1}\right) \mid T\left(M_{L-2}\right)\right]\right.\right. \\
& \left.\left.\left\{\cdots\left\{\sum_{T\left(M_{1}\right) \in \Omega_{1}} P\left[T\left(M_{2}\right) \mid T\left(M_{1}\right)\right] . P T T\left(M_{1}\right)\right]\right\}\right\} \cdots\right\}
\end{aligned}
$$

Consequently:

$$
\begin{aligned}
& \text { If } \quad F\left[T\left(M_{1}\right)\right]=P\left[T\left(M_{1}\right)\right] \\
& \text { then } F\left[T\left(M_{2}\right)\right]=\sum_{T\left(M_{1}\right) \in \Omega_{1}} P\left[T\left(M_{2}\right) \mid T\left(M_{1}\right)\right] \cdot F\left[T\left(M_{1}\right)\right] \\
& F\left[T\left(M_{l}\right)\right]=\sum_{T\left(M_{l-1}\right) \in \Omega_{l-1}} P\left[T\left(M_{l}\right) \mid T\left(M_{l-1}\right)\right] . F\left[T\left(M_{l-1}\right)\right] \\
& \text { And } \quad S_{\Omega}=\sum_{T\left(M_{L}\right) \in \Omega_{L}} F\left[T\left(M_{L}\right)\right]
\end{aligned}
$$

\section{Proposition 3}

With an argument similar to the demonstration of proposition 2, the sum $S_{\Omega}$ may be expressed as:

$$
S_{\Omega}=\sum_{T\left(M_{b}\right) \in \Omega_{b}} \sum_{T\left(M_{\beta}\right) \in \Omega_{\beta}} P\left[T\left(M_{b}\right) \mid T\left(M_{\beta}\right)\right] \cdot F\left[T\left(M_{\beta}\right)\right]
$$

$F\left[T\left(M_{\beta}\right)\right]=\sum_{T\left(M_{c}\right) \in \Omega_{c}} P\left[T\left(M_{\beta}\right) \mid T\left(M_{c}\right)\right] \cdot F\left[T\left(M_{c}\right)\right]$

$=\sum_{T\left(M_{c} \in \Omega_{c}\right.} P\left[T\left(M_{\beta}\right) \mid T\left(M_{c}\right)\right] \cdot\left\{\sum_{T\left(M_{\alpha}\right) \in \Omega_{\alpha}} P\left[T\left(M_{c}\right) \mid T\left(M_{\alpha}\right)\right] \cdot F\left(\left[T\left(M_{\alpha}\right)\right]\right\}\right.$

$=\sum_{T\left(M_{\alpha}\right) \in \Omega_{\alpha}}\left\{\sum_{T\left(M_{c} \in \mathcal{E}_{e}\right.} P\left[T\left(M_{\beta}\right) \mid T\left(M_{c}\right)\right] \cdot P\left[T\left(M_{c}\right) \mid T\left(M_{\alpha}\right)\right\}\right\} \cdot F\left(T\left(M_{\alpha}\right)\right]$

$=\sum_{T\left(M_{\alpha} \in \Omega_{\alpha}\right.}\left\{\sum_{T\left(M_{c} \in \Omega_{c}\right.} P\left[T\left(M_{\beta}\right), T\left(M_{c}\right) \mid T\left(M_{\alpha}\right)\right]\right\} \cdot F\left(\left[T\left(M_{\alpha}\right)\right]\right.$

$=\sum_{T\left(M_{\alpha}\right) \in \Omega_{\alpha}}\left\{\sum_{T\left(M_{\alpha} \in \Omega_{\alpha}\right.} P\left[T\left(M_{c}\right) \mid T\left(M_{\beta}\right), T\left(M_{\alpha}\right)\right]\right\} \cdot P\left[T\left(M_{\beta}\right) \mid T\left(M_{\alpha}\right)\right] \cdot F\left[T\left(T\left(M_{\alpha}\right)\right]\right.$

Thus

$F\left[T\left(M_{\beta}\right)\right]=\sum_{T\left(M_{\alpha}\right) \in \Omega_{\alpha}}\left\{\sum_{T\left(M_{c}\right) \in \Omega_{c}} P\left[T\left(M_{c}\right) \mid T\left(M_{\beta}\right), T\left(M_{\alpha}\right)\right]\right\} \cdot P\left[T\left(M_{\beta} \mid T\left(M_{\alpha}\right)\right] \cdot F\left(\left[T\left(M_{\alpha}\right)\right]\right.\right.$

As $\Omega_{c}$ forms a complete set of events, since all transmissions are possible,

$$
\sum_{T\left(M_{c}\right) \in \Omega_{c}} P\left[T\left(M_{c}\right) \mid T\left(M_{\beta}\right), T\left(M_{\alpha}\right)\right]=1
$$

Thus

$$
F\left[T\left(M_{\beta}\right)\right] \sum_{T\left(M_{\alpha}\right) \in \Omega_{\alpha}} P\left[T\left(M_{\beta}\right) \mid T\left(M_{\alpha}\right)\right] \cdot F\left(\left[T\left(M_{\alpha}\right)\right]\right.
$$

\section{Proposition 4}

In the equation(A1), we have, from property 1 ,

$P\left[T\left(M_{c}\right) \mid T\left(M_{\beta}\right), T\left(M_{\alpha}\right)\right]=P\left[T\left(M_{s c}\right) \mid T\left(M_{s \beta}\right), T\left(M_{s \alpha}\right)\right] \cdot P\left[T\left(M_{d c}\right) \mid T\left(M_{d \beta}\right), T\left(M_{d \alpha}\right)\right]$ Without loss of generality, we assume that the parent with unknown transmission at $M_{c}$ is the sire. There is a unique consistent $T\left(M_{d c}\right)$, and the 2 possible $T\left(M_{s c}\right)$ form a complete set of events, thus:

$$
\sum_{T\left(M_{c}\right) \in \Omega_{c}} P\left[T\left(M_{c}\right) \mid T\left(M_{\beta}\right), T\left(M_{\alpha}\right)\right]=P\left[T\left(M_{d c}\right) \mid T\left(M_{d \beta}\right), T\left(M_{d \alpha}\right)\right]
$$

The simplification of $F\left[T\left(M_{\beta}\right)\right]$ follows:

$$
\begin{aligned}
F\left[T\left(M_{\beta}\right)\right] & =\sum_{T\left(M_{\alpha}\right) \in \Omega_{\alpha}} P\left[T\left(M_{d c}\right) \mid T\left(M_{d \beta}\right), T\left(M_{d \alpha}\right)\right] \cdot P\left[T\left(M_{\beta}\right) \mid T\left(M_{\alpha}\right)\right] \cdot F\left[T\left(M_{\alpha}\right)\right] \\
& =\sum_{T\left(M_{\alpha}\right) \in \Omega_{\alpha}} P\left[T\left(M_{d c}\right) \mid T\left(M_{d \beta}\right), T\left(M_{d \alpha}\right)\right] \cdot P\left[T\left(M_{d \beta}\right) \mid T\left(M_{d \alpha}\right)\right] \cdot P\left[T\left(M_{s \beta}\right) \mid T\left(M_{s \alpha}\right)\right] \cdot F\left[T\left(M_{\alpha}\right)\right] \\
& =\sum_{T\left(M_{\alpha}\right) \in \Omega_{\alpha}} P\left[T\left(M_{d \beta}\right) \mid T\left(M_{d c}\right)\right] \cdot P\left[T\left(M_{d c}\right) \mid T\left(M_{d \alpha}\right)\right] \cdot P\left[T\left(M_{s \beta}\right) \mid T\left(M_{s \alpha}\right)\right] \cdot F\left[T\left(M_{\alpha}\right)\right]
\end{aligned}
$$

\section{Proposition 5}

When $M_{c}$ contains markers of $k 00$ type, they can be forgotten following proposition 3 . We thus assume that the $M_{c}$ group is empty, and the linkage group is described as $M=$ $\left\{M_{b^{\prime}}, M_{\beta^{\prime}} M_{\alpha^{\prime}} M_{a}\right\}$

$$
S_{\Omega}=\sum_{T\left(M_{b}\right) \in \Omega_{b}} \sum_{T\left(M_{\beta}\right) \in \Omega_{\beta}} \sum_{T\left(M_{\alpha}\right) \in \Omega_{\alpha}} \sum_{T\left(M_{a}\right) \in \Omega_{a}} P\left[T\left(M_{b}\right), T\left(M_{\beta}\right), T\left(M_{\alpha}\right), T\left(M_{a}\right)\right]
$$

$P\left[T\left(M_{b}\right), T\left(M_{\beta}\right), T\left(M_{\alpha}\right), T\left(M_{a}\right)\right]=$

$P\left[T\left(M_{b}\right), T\left(M_{d \beta}\right) \mid T\left(M_{s \beta}\right), T\left(M_{\alpha}\right), T\left(M_{a}\right)\right] \cdot P\left[T\left(M_{s \alpha}\right), T\left(M_{a}\right) \mid T\left(M_{s \beta}\right), T\left(M_{d \alpha}\right)\right] \cdot P\left[T\left(M_{s \beta}\right) \mid T\left(M_{d \alpha}\right)\right]$ 
But $P\left[T\left(M_{b}\right), T\left(M_{d \beta}\right) \mid T\left(M_{s \beta}\right), T\left(M_{\alpha}\right), T\left(M_{a}\right)\right]=P\left[T\left(M_{b}\right)\right.$, $\left.T\left(M_{d \beta}\right) \mid T\left(M_{s \beta}\right), T\left(M_{d \alpha}\right)\right]$

Thus

$$
\begin{array}{r}
S_{\Omega}=\sum_{T\left(M_{b}\right) \in \Omega_{b}} \sum_{T\left(M_{\beta}\right) \in \Omega_{\beta}} \sum_{T\left(M_{\alpha}\right) \in \Omega_{\alpha}} \sum_{T\left(M_{a}\right) \in \Omega_{a}} P\left[T\left(M_{b}\right) \cdot T\left(M_{d \beta}\right) \mid T\left(M_{s \beta}\right), T\left(M_{d \alpha}\right)\right] . \\
P\left[T\left(M_{s \alpha}\right), T\left(M_{a}\right) \mid T\left(M_{s \beta}\right), T\left(M_{d \alpha}\right)\right] \cdot P\left[T\left(M_{s \beta}\right) \mid T\left(M_{d \alpha}\right)\right] \\
=\left\{\sum_{T\left(M_{b}\right) \in \Omega_{b}} \sum_{T\left(M_{\beta}\right) \in \Omega_{\beta}} P\left[T\left(M_{b}\right) \cdot T\left(M_{d \beta}\right) \mid T\left(M_{s \beta}\right), T\left(M_{d \alpha}\right)\right]\right\} \cdot P\left[T\left(M_{s \beta}\right) \mid T\left(M_{d \alpha}\right)\right] . \\
\left\{\sum_{T\left(M_{\alpha}\right) \in \Omega_{\alpha}} \sum_{T\left(M_{\alpha}\right) \in \Omega_{\alpha}} P\left[T\left(M_{s \alpha}\right) \cdot T\left(M_{a}\right) \mid T\left(M_{s \beta}\right), T\left(M_{d \alpha}\right)\right]\right\}
\end{array}
$$

Corollary 2

Let $M=\left\{M_{b}, N_{l}, M_{c}, N_{r}, M_{a}\right\}$, with $x\left(N_{l}\right) \leq x \leq x\left(N_{r}\right)$

From proposition 5, assuming both nodes $N_{l}$ and $N_{r}$ are sd-nodes,

$S_{\Omega}=\left\{\sum_{T\left(M_{b}\right) \in \Omega_{b}} P\left[T\left(M_{b}\right) \mid T\left(N_{l}\right)\right]\right\} . P\left[T\left(N_{l}\right)\right] \cdot\left\{\sum_{T\left(M_{c}\right) \in \Omega_{c}} \sum_{T\left(M_{a}\right) \in \Omega_{a}} P\left[T\left(M_{c}\right), T\left(N_{r}\right), T\left(M_{a}\right) \mid T\left(N_{l}\right)\right]\right\}$

From proposition 5 again,

$\sum_{T\left(M_{c}\right) \in \Omega_{c}} \sum_{T\left(M_{a}\right) \in \Omega_{a}} P\left[T\left(M_{c}\right), T\left(N_{r}\right), T\left(M_{a}\right) \mid T\left(N_{l}\right)\right]=$

$\left\{\sum_{T\left(M_{c}\right) \in \Omega_{c}} P\left[T\left(M_{c}\right) \mid T\left(N_{l}\right), T\left(N_{r}\right)\right]\right\} . P\left[T\left(N_{r}\right) \mid T\left(N_{l}\right)\right] \cdot\left\{\sum_{T\left(M_{a}\right) \in \Omega_{a}} P\left[T\left(M_{a}\right) \mid T\left(N_{l}\right), T\left(N_{r}\right)\right]\right\}$

The elements $\quad \sum_{T\left(M_{b}\right) \in \Omega_{b}} P\left[T\left(M_{b}\right) \mid T\left(N_{l}\right)\right] \quad$ and $\sum_{T\left(M_{a}\right) \in \Omega_{a}} P\left[T\left(M_{b}\right) \mid T\left(N_{l}\right), T\left(N_{r}\right)\right]$ being also present in the numerator $T_{\Omega}$ of (1) they can be forgotten.

The summation $S_{\Omega}$ may be reduced to $S_{\Omega}^{r}$ :

$$
\begin{aligned}
S_{\Omega}^{r} & =P\left[T\left(N_{l}\right)\right] \cdot\left\{\sum_{T\left(M_{c}\right) \in \Omega_{c}} P\left[T\left(M_{c}\right) \mid T\left(N_{l}\right), T\left(N_{r}\right)\right]\right\} \cdot P\left[T\left(N_{r}\right) \mid T\left(N_{l}\right)\right] \\
& =\sum_{T\left(M_{c}\right) \in \Omega_{c}} P\left[T\left(M_{c}\right), T\left(N_{l}\right), T\left(N_{r}\right)\right]
\end{aligned}
$$

Similarly

$$
T_{\Omega}^{r}=\sum_{T\left(M_{c}\right) \in \Omega_{c}} P\left[T\left(Q_{x}\right), T\left(N_{l}\right), T\left(M_{c}\right), T\left(N_{r}\right)\right]
$$

\section{Acknowledgements}

Financial support of this work was provided by the EC-funded FP6 Project "SABRE".

\section{References}

I. Lander ES, Botstein D: Mapping mendelian factors underlying quantitative traits using RFLP linkage maps. Genetics 1989, | 21:185-199.

2. Liu JM, Jansen GB, Lin CY: The covariance between relatives conditional on genetic markers. Genet Sel Evol 2002, 34:657-678.

3. Pong-Wong R, George AW, Woolliams JA, Haley CS: A simple and rapid method for calculating identity-by-descent matrices using multiple markers. Genet Sel Evol 2002, 33:453-47I.

4. Haley CS, Knott SA, Elsen JM: Mapping quantitative trait loci in crosses between outbred lines using least squares. Genetics 1994, 136: I195-1207.
5. Knott SA, Elsen JM, Haley CS: Methods for multiple marker mapping of quantitative trait loci in half-sib populations. Theor Appl Genet 1996, 93:71-80.

6. Elsen JM, Mangin B, Goffinet B, Boichard D, Le Roy P: Alternative models for QTL detection in livestock - I General introduction. Genet Sel Evol 1999, 31:21 3-224.

7. Le Roy P, Elsen JM, Boichard D, Mangin B, Bidanel JP, Goffinet B: An algorithm for $Q T L$ detection in mixture of full and half sib families. Proceedings of the 6th World Congress on Genetics Applied to Livestock Production: I 2-16 January 1998; Armidale Australia 1998.

8. Totir LR, Fernando RL, Dekkers JC, Fernández SA, Guldbrandtsen B: A comparison of alternative methods to compute conditional genotype probabilities for genetic evaluation with finite locus models. Genet Sel Evol 2003, 35:585-604.

9. Nettelblad C, Holmgren S, Crooks L, Carlborg O: cnF2freq: Efficient Determination of Genotype and Haplotype Probabilities in Outbred Populations Using Markov Models. BICoB 2009:307-319.

10. Elsen JM, Filangi O, Gilbert H, Legarra A, Le Roy P, Moreno C: QTLMap: a software for the detection of QTL in full and half sib families. Proceedings of the EAAP Annual meeting 24-27 August 2009; Barcelona 2009.

II. Windig |J, Meuwissen THE: Rapid haplotype reconstruction in pedigrees with dense marker maps. J Anim Breed Genet 2004, 121:2639.
Publish with BioMed Central and every scientist can read your work free of charge

"BioMed Central will be the most significant development for disseminating the results of biomedical research in our lifetime. "

Sir Paul Nurse, Cancer Research UK

Your research papers will be:

- available free of charge to the entire biomedical community

- peer reviewed and published immediately upon acceptance

- cited in PubMed and archived on PubMed Central

- yours - you keep the copyright
BioMedcentral 